\title{
Aplicação foliar de aminoácidos e adubação nitrogenada de cobertura na cultura do milho safrinha
}

\author{
Diego Gazola ${ }^{1}$, Claudemir Zucareli ${ }^{2}$, Raphael R. Silva ${ }^{3} \&$ Ines C. de B. Fonseca ${ }^{4}$
}

${ }^{1}$ UEL. Londrina, PR. E-mail: gazolad@hotmail.com (Autor correspondente)

${ }^{2}$ UEL. Londrina, PR. E-mail: claudemircca@uel.br

${ }^{3}$ UEL. Londrina, PR. E-mail: rossi.raphael@outlook.com

${ }^{4}$ UEL. Londrina, PR. E-mail: inescbf@uel.br

\section{Palavras-chave:}

adubação complementar proteína colagênica animal resíduo agroindustrial ureia

Zea mays

\begin{abstract}
R E S U M O
Neste trabalho se objetivou avaliar a aplicação foliar de aminoácidos associada à aplicação de nitrogênio em cobertura, no desempenho produtivo e nas características agronômicas da cultura do milho, cultivado no período da safrinha. O delineamento foi o de blocos ao acaso, em esquema fatorial 4 x 4, com 4 repetições. Foram utilizadas quatro doses de nitrogênio em cobertura $\left(0,60,120\right.$ e $\left.180 \mathrm{~kg} \mathrm{ha}^{-1}\right)$ na forma de ureia e quatro doses de aminoácido $(0,8,16$, e $24 \mathrm{~L} \mathrm{ha}^{-1}$ ) aplicadas via foliar. A cultivar de milho utilizado foi o Pioneer $30531 \mathrm{H}$. As variáveis analisadas foram teor de nitrogênio foliar, altura de plantas, altura de espiga, diâmetro do colmo, comprimento de espiga, número de fileiras de grãos por espiga, número de grãos por fileira, número de grãos por espiga, massa de 100 grãos e produtividade de grãos. $\mathrm{O}$ aminoácido não alterou as variáveis analisadas. O nitrogênio incrementou linearmente as variáveis altura de plantas, altura de inserção de espiga, número de grãos por espiga e número de grãos por fileira. O comprimento de espiga, a massa de mil grãos e a produtividade de grãos obtiveram, respectivamente, máxima resposta ao nitrogênio nas doses de 135,3, 157 e 149,5 $\mathrm{kg} \mathrm{ha}^{-1}$.
\end{abstract}

Key words: additional fertilizers agro waste animal protein collagen urea Zea mays

\section{Foliar application of aminoacids and nitrogen as topdressing on second corn crop}

\begin{abstract}
A B S T R A C T
The objective of this study was to evaluate the foliar application of amino acids associated with the application of nitrogen as topdressing on yield performance and agronomic characteristics of corn, cultivated during the latter season. The experimental design was a randomized block design in a $4 \times 4$ factorial, with 4 repetitions. Four doses of nitrogen $\left(0,60,120\right.$ and $\left.180 \mathrm{~kg} \mathrm{ha}^{-1}\right)$ as urea were used and four doses of amino acids $\left(0,8,16\right.$, and $\left.24 \mathrm{~L} \mathrm{ha}^{-1}\right)$ were applied on leaves. The maize cultivar used was Pioneer $30531 \mathrm{H}$. The variables analysed were: leaf $\mathrm{N}$ content, plant height, ear height, stem diameter, ear length, number of kernel rows per ear, number of kernels per row, number of grains per spike, weight of 100 grains and yield. The amino acids did not alter the analysed variables. Nitrogen increased linearly the variables plant height, height of insertion of ear, number of grains per ear and number of kernels per row. The length of spike, thousand grain weight and grain yield response to nitrogen obtained under maximum doses of $135.3,157$ and $149.5 \mathrm{~kg} \mathrm{ha}^{-1}$, respectively.
\end{abstract}

\section{INTRODUÇÃo}

O milho (Zea mays) é um dos cereais mais importantes cultivados e consumidos no mundo devido ao seu potencial produtivo, composição química e valor nutritivo. Em virtude da sua multiciplidade de aplicações até a indústria de alta tecnologia assume relevante papel socioeconômico; além disto se constitui em matéria-prima indispensável impulsionadora de diversificados complexos agroindustriais (Fancelli \& Dourado Neto, 2008).

O Brasil é o terceiro maior produtor mundial totalizando 72 milhões de toneladas na safra 2011/2012 e está entre os países que terão aumento significativo das exportações de milho, ao lado da Argentina. O Paraná é o maior estado produtor da cultura com mais de 16 milhões de t ha ${ }^{-1} \mathrm{com}$ uma área cultivada de 12.247,7 milhões de hectares contando com uma das maiores produtividades brasileiras, de $5.448 \mathrm{~kg} \mathrm{ha}^{-1}$ (CONAB, 2012).

Grande parte da produção nacional, cerca de $48,5 \%$ são devidos ao milho de segunda safra ou safrinha totalizando 32 milhões de toneladas. Só o estado do Paraná é responsável por $29 \%$ do total de milho produzido neste período (CONAB, 2012). O milho safrinha é caracterizado pelo cultivo em sequeiro, com semeadura realizada nos meses de janeiro a abril, após a cultura de verão, geralmente após soja precoce (Cruz et al., 2011).

$\mathrm{O}$ nitrogênio $(\mathrm{N})$ é o nutriente mais exigido pela cultura do milho desempenhando importante papel no acúmulo de 
proteína e na produtividade de grãos (Pavinato et al., 2008), aumenta o peso da espiga e a porcentagem de óleo. Por outro lado, está associado ao crescimento vegetativo, participa de mecanismos da fotossíntese, faz parte das moléculas de clorofila, aminoácidos, DNA, citocromos e de todas as enzimas e coenzimas (Fancelli \& Dourado Neto, 2008).

Os fertilizantes nitrogenados são produzidos sobretudo a partir de combustíveis fósseis e $\mathrm{N}_{2}$, não renováveis $\mathrm{e}$ quando utilizados em quantidades excessivas ou situações desfavoráveis podem ser perdidos por volatilização ou lixiviação e, eventualmente, se convertem em poluentes ambientais (Cantarella \& Marcelino, 2008).

Sabe-se que, na prática, a adubação foliar é de complemento à adubação feita no solo, no que diz respeito ao fornecimento de nitrogênio, fósforo e potássio para as culturas. Deste modo, a incorporação de $\mathrm{N}$ via adubação foliar com aminoácidos pode suplementar o fornecimento via solo em determinados estágios de crescimento. O uso de fertilização direta nas plantas com aminoácidos livres reduz a transformação química do nitrogênio nítrico e amoniacal em aminoácidos. Além disso, os aminoácidos são rapidamente incorporados ao metabolismo como se fossem sintetizados pela planta contribuindo para o processo de desenvolvimento e crescimento (Lima et al., 2009).

O objetivo do trabalho foi estudar os efeitos da aplicação foliar de aminoácidos associados à aplicação de doses de nitrogênio em cobertura, no desempenho produtivo e nas características agronômicas da cultura do milho safrinha.

\section{Material e Métodos}

O experimento foi conduzido no período de cultivo da safrinha em 2012, em sistema de plantio direto na Fazenda Escola da Universidade Estadual de Londrina/Paraná (latitude $23^{\circ} 20^{\prime} 23^{\prime \prime} \mathrm{S}$ e longitude $51^{\circ} 12^{\prime} 32^{\prime \prime} \mathrm{W}$ ) com altitude média de $580 \mathrm{~m}$. Conforme classificação climática de Koppen, o clima da região é do tipo Cfa, clima subtropical úmido mesotérmico, com verões quentes e geadas pouco frequentes, com tendência de concentração de chuvas nos meses de verão e sem estação seca definida. A temperatura média anual, segundo o IAPAR, é de $20,2{ }^{\circ} \mathrm{C}$, a média da temperatura máxima é de $27,0{ }^{\circ} \mathrm{C}$ e a média da temperatura mínima é de $14,8^{\circ} \mathrm{C}$. A umidade relativa do ar é de $75 \%$.

Os dados climáticos durante a condução do experimento obtidos na estação meteorológica do IAPAR, constam na Figura 1.

O solo onde foi conduzido o experimento é do tipo Nitossolo Vermelho eutroférrico latossólico, com fertilidade e retenção de água mediana, textura argilosa, boa drenagem, lençol freático muito profundo e baixo teor de matéria orgânica.

O delineamento utilizado foi o de blocos ao acaso, em esquema fatorial $4 \times 4$, com quatro repetições. Foram avaliadas quatro doses de nitrogênio em cobertura $(0,60,120$ e $180 \mathrm{~kg}$ $\left.\mathrm{ha}^{-1}\right)$ na forma de ureia, aplicadas no estádio vegetativo v5 e quatro doses de aminoácidos $\left(0,8,16\right.$, e $\left.24 \mathrm{~L} \mathrm{ha}^{-1}\right)$ aplicadas via foliar durante o estádio vegetativo V6. A parcela foi composta

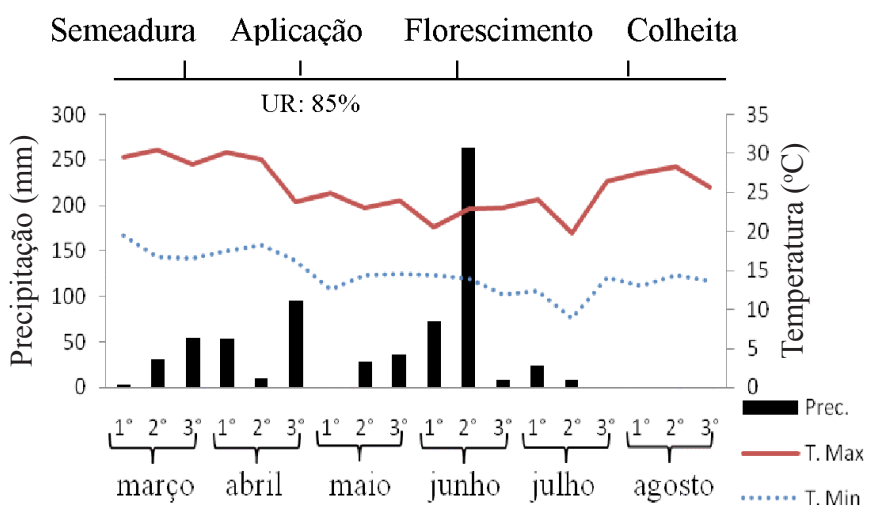

Figura 1. Precipitação e médias das temperaturas máximas e mínimas, por decêndio, durante a condução do experimento de milho safrinha 2012

de quatro linhas de milho espaçadas com 0,90 m, com cinco metros cada uma totalizando uma área total de $18 \mathrm{~m}^{2}$. Para as avaliações foram utilizadas apenas as duas linhas centrais totalizando $9 \mathrm{~m}^{2}$ de área útil.

A aplicação do produto à base de aminoácido na forma líquida foi realizada no período da manha com umidade relativa do ar de $85 \%$ e com o auxílio de um pulverizador costal de $\mathrm{CO}_{2}$, além de uma barra de aplicação de dois metros. $\mathrm{O}$ aminoácido de cada parcela referente à dose pré-estipulada foi diluído em $500 \mathrm{~mL}$ de água com o auxílio de uma proveta graduada e acondicionados em garrafas tipo pet para serem acoplados ao pulverizador costal e deste modo aplicados sobre a cultura.

Segundo a empresa fornecedora, o produto é uma linha de aditivos que podem ter seu uso de forma líquida (via foliar) e sólida (via raiz) com alta concentração de nutrientes orgânicos cujo princípio ativo principal contém aminoácidos originados de resíduo agroindustrial da proteína colagênica animal.

Os aminoácidos presentes no produto comercial na forma líquida e suas respectivas concentrações são: L-Glicina (5,08\%); L-Prolina (2,94\%); L-Alanina (2,02\%); L-Ácido Glutâmico (2,28\%); L-Ácido Aspártico (1,34\%); L-Arginina (1,56\%); L-Serina (0,65\%); L-Leucina (0,65\%); L-Lisina $(0,48 \%)$; L-Valina (0,53\%); L-Treonina (0,30\%); L-Fenilalanina (1,13\%); L-Isoleucina (0,34\%); L-Tirosina (0,14\%) e L-Histidina $(0,16 \%)$.

Ainda segundo o fornecedor, o produto pode ser absorvido via sistema radicular, pelas folhas, caules e ramos. O produto é 100\% solúvel em água e biodegradável, é atóxico, não agride a fauna nem a flora, sem nenhuma substância derivada do petróleo e livre de metais pesados. A recomendação do produto para a cultura do milho é de 6 a $8 \mathrm{~L} \mathrm{ha}^{-1}, 15-20$ dias após a emergência e/ou 30-35 dias após emergência.

A cultivar de milho utilizada na safrinha foi a Pioneer $30531 \mathrm{H}$ semeada de forma mecanizada com emergência das plântulas 5 dias após a semeadura e uma população de $60 \mathrm{mil}$ plantas ha ${ }^{-1}$.

A adubação de semeadura foi baseada na análise química do solo utilizando-se $250 \mathrm{~kg} \mathrm{ha}^{-1}$ do formulado 4-14-8, conforme análise de solos (Tabela 1). 
Tabela 1. Análise de solos realizada na área de condução do experimento, na profundidade de $0-20 \mathrm{~cm}$, na fazenda escola da Universidade Estadual de Londrina

\begin{tabular}{|c|c|c|c|c|c|c|c|c|c|c|c|c|c|}
\hline \multirow{3}{*}{$\begin{array}{c}\text { Prof. } \\
\text { cm } \\
0-20\end{array}$} & \multirow{3}{*}{$\begin{array}{c}P \\
\mathrm{mg} \mathrm{dm}^{-3}\end{array}$} & \multirow{3}{*}{$\begin{array}{c}\text { C } \\
\text { g dm } \\
5928\end{array}$} & \multirow{2}{*}{$\begin{array}{c}\mathrm{pH} \\
\left(\mathrm{CaCl}_{2}\right)\end{array}$} & Al & $\mathbf{H}+\mathbf{A l}$ & $\mathrm{Ca}$ & $\mathrm{Mg}$ & K & SB & CTC & V & SAI & MO \\
\hline & & & & \multicolumn{7}{|c|}{$\mathrm{cmol}_{\mathrm{c}} \mathrm{dm}^{-3}$ de solo } & \multicolumn{3}{|c|}{$\%$} \\
\hline & & & 4,9 & 0 & 6,2 & 4,62 & 2,17 & 0,45 & 7 & 13,34 & 53,7 & 0 & 2,928 \\
\hline
\end{tabular}

pH - pH em cloreto de cálcio; SB - Soma de bases; CTC - Capacidade de trocar cátions a pH 7,0; V - Saturação por bases; M0 - Matéria orgânica; SAL - Saturação de alumínio

Durante os experimentos não foi necessária a aplicação de defensivos agrícolas para doenças e insetos pragas. $\mathrm{O}$ controle de plantas daninhas foi realizado de forma manual, no momento de aplicação da ureia em cobertura. A fonte de $\mathrm{N}$ utilizada em cobertura foi a ureia (45\%), aplicada uma semana antes da aplicação do aminoácido, no estádio V5, a lanço em cada parcela.

A colheita foi realizada de forma manual. Os parâmetros analisados foram: a) Teor foliar de nitrogênio - foram coletados ao acaso, no estádio de florescimento pleno, os limbos foliares de cinco folhas diagnóstico, opostas e abaixo da espiga da área útil de cada parcela que, por sua vez, foram acondicionados em sacos de papel devidamente identificados e levados ao laboratório onde foram submetidas à secagem em estufa de ventilação forçada em temperatura média de $65^{\circ} \mathrm{C}$ até atingir a massa em equilíbrio. Após a secagem as folhas coletadas foram moídas e submetidas a digestão sulfúrica conforme metodologia descrita por Kjeldahl (Bremner, 1996) para determinação do teor de nitrogênio foliar; b) População de plantas - obtida através da contagem do número de plantas, na pré-colheita das duas linhas centrais de cada parcela; c) Altura de plantas e Altura de inserção de espigas - medida no estádio de pré-colheita, definida como sendo a distância $(\mathrm{cm})$ do nível do solo ao ápice da planta de milho, para altura de planta e até a altura da espiga principal para altura de inserção de espiga. Foram medidas cinco plantas ao acaso representativas da área útil de cada parcela; d) Diâmetro do colmo - obtido na précolheita com auxílio de um paquímetro analógico, medidos no segundo entrenó a partir do nível do solo. Foram medidas cinco plantas ao acaso representativas da área útil de cada parcela; e) Comprimento de espiga - foi realizado após a colheita separando-se aleatoriamente dez espigas colhidas na área útil de cada parcela as quais foram medidas por meio de uma régua graduada com resultados expressos em $\mathrm{cm}$; f) Número de fileiras de grãos - determinado por meio de contagem em 10 espigas tomadas ao acaso na área útil de cada parcela; g) Número de grãos por fileira - determinado mediante contagem dos grãos nas fileiras das 10 espigas amostradas aleatoriamente em cada parcela; h) Número de grãos por espiga - calculado por meio do produto do número de grãos presentes nas fileiras e número de fileiras de grãos, das espigas amostradas aleatoriamente em cada parcela; i) Massa de 1000 grãos - após a debulha determinou-se a massa de mil grãos por meio de três amostras de 100 grãos tomadas ao acaso, de cada parcela, as quais foram submetidas à pesagem e à determinação imediata da umidade; j) Produtividade - foi obtida a partir da debulha e da pesagem dos grãos oriundos de todas as espigas colhidas na área útil das unidades experimentais $\left(\mathrm{kg} \mathrm{parcela}^{-1}\right)$ a qual foi convertida para $\mathrm{kg} \mathrm{ha}^{-1}$ e corrigida para $13 \%$ de umidade.
Os dados foram submetidos à análise de normalidade e homogeneidade dos resíduos pelo teste de Shapiro-Wilk e Bartlett, respectivamente, considerando-se o nível de 0,05 de significância e só então analisados por análise de variância (ANAVA) e regressão, até $2^{\circ}$ grau.

\section{Resultados e Discussão}

Não foram constatados efeitos significativos para as doses de aminoácidos aplicadas via foliar tampouco para a interação entre os fatores aminoácido foliar e doses de nitrogênio em cobertura.

Contrariando os resultados obtidos nesse estudo para o milho Picolli et al. (2009) concluíram, ao estudar a aplicação de produtos à base de aminoácidos como tratamento de sementes e na fase de perfilhamento na cultura do trigo que esses produtos proporcionaram não apenas ganhos significativos em produtividade de grãos mas também benefícios à cultura em situações adversas ao clima, como o déficit hídrico; apesar disto os autores não aplicaram $\mathrm{N}$ em semeadura o que beneficiou os aminoácidos aplicados visto que eles foram a única fonte de nutrientes fornecida para a cultura.

A época de aplicação pode ter influenciado o resultado de vez que, além da aplicação única (em estádio v3 ou v6) a empresa fornecedora do produto também recomenda a aplicação em dois estádios desenvolvimento: 15-20 dias após a emergência (V3) e 30-35 (V6) dias após emergência; deste modo, a aplicação em apenas um estádio pode ter resultado em menor absorção do produto.

Respostas significativas ocorreram apenas em função das doses de nitrogênio aplicadas em cobertura. Nas variáveis diâmetro do colmo e população de plantas avaliadas em précolheita, não houve efeito significativo do nitrogênio aplicado em cobertura. Meira et al. (2009) também não observaram diferença significativa para o diâmetro do colmo do híbrido AGN 20A20 avaliando três fontes de $\mathrm{N}$ e cinco doses em semeadura e cobertura, em Selvíria/MS e ainda ressaltam que esta é uma característica altamente influenciada pelo genótipo e pouco dependente do meio, quando não se varia a densidade de plantas.

A aplicação de diferentes doses de $\mathrm{N}$ influenciou significativamente a altura de inserção da espiga e de plantas de milho (Figura 2). A altura de plantas apresentou ajuste linear crescente em resposta à aplicação de $\mathrm{N}$. Na testemunha a altura média das plantas foi de 198,68 cm, isto é, a menor medida quando comparada com as demais. A maior altura das plantas foi observada com a dose máxima de nitrogênio aplicada, de $180 \mathrm{~kg} \mathrm{ha}^{-1}$ com $219,31 \mathrm{~cm}$, não sendo possível determinar o ponto de máxima resposta. 


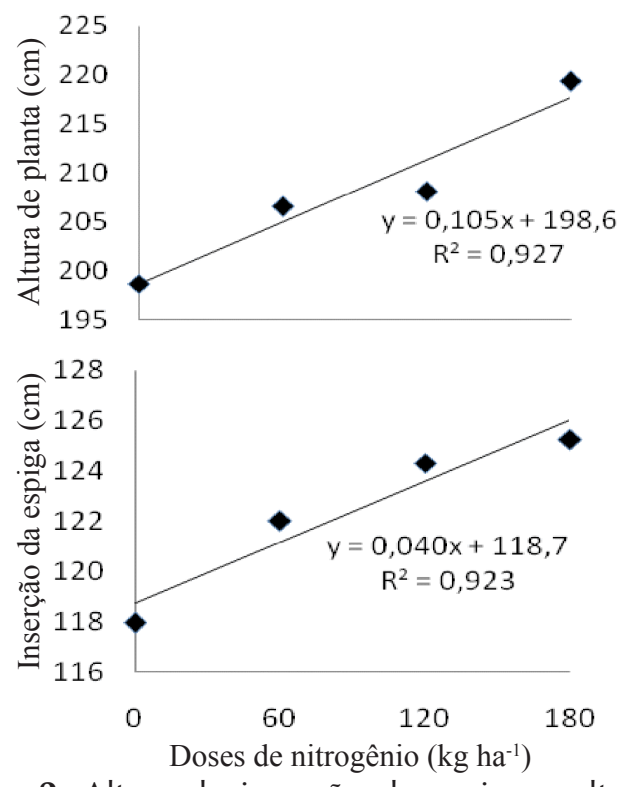

Figura 2. Altura de inserção da espiga e altura de plantas em função de doses de nitrogênio aplicadas na cultura do milho Safrinha

Para altura de inserção das espigas o efeito das doses de $\mathrm{N}$ foi semelhante ao observado para altura de plantas. Ocorreu efeito linear crescente com o aumento do $\mathrm{N}$ aplicado em cobertura. Neumann et al. (2005) verificaram, ao estudar o desempenho produtivo do milho híbrido Dow 766, em Guarapuava, com diferentes doses de N $\left(0,45,90,135 \mathrm{~kg} \mathrm{ha}^{-1}\right)$ que houve aumento da altura de plantas e da altura da inserção da espiga até a dose de $90 \mathrm{~kg} \mathrm{ha}^{-1}$ com médias de 2,14 e 1,27 cm respectivamente, demonstrando resultados semelhantes aos deste experimento.

$\mathrm{O}$ nitrogênio exerce funções relevantes no metabolismo vegetal e é integrante de todos os aminoácidos fazendo parte da constituição das proteínas; está relacionado ao crescimento e ao rendimento da planta. Isso se deve principalmente ao fato deste nutriente estar associado ao crescimento e ao desenvolvimento dos drenos reprodutivos e por participar na molécula de clorofila, indispensável para a manutenção da atividade fotossintética (Basi et al., 2011). Deste modo, o $\mathrm{N}$ atua no crescimento vegetativo influenciando diretamente a divisão e a expansão celular e o processo fotossintético, promovendo acréscimo em altura de planta e de espiga (Silva et al., 2005) como observado neste estudo.

Plantas maiores tendem a ser mais produtivas pelo fato de sofrerem menos estresse durante o desenvolvimento e acumular maiores quantidades de reserva no colmo (Silva et al., 2006). Contudo, a maior estatura de plantas e a inserção da espiga no colmo contribuem para o aumento do acamamento da cultura (Brachtvogel et al., 2012). A deficiência de N retarda a divisão celular nos pontos de crescimento do milho resultando em redução na área foliar e no tamanho da planta, conforme constatado, com reflexos negativos sobre a produção (Fancelli \& Dourado Neto, 2008).

Lana et al. (2009) concluíram, para cada $30 \mathrm{~kg}$ de $\mathrm{N}$ adicionado, aumento das alturas de planta e de inserção de espiga de 2,1 e 1,8 cm, respectivamente. Valores próximos aos encontrados neste estudo, em que a cada $30 \mathrm{~kg}$ de $\mathrm{N}$ adicionado em cobertura, a altura de planta aumentou $3,4 \mathrm{~cm}$ e a altura da inserção da espiga, $1,2 \mathrm{~cm}$.

Quanto aos componentes de produção apenas o número de fileiras por espiga não apresentou efeito significativo em resposta às doses de $\mathrm{N}$. O comportamento do comprimento de espiga, o número de grãos, o número de grãos por espiga e o número de grãos por fileira e massa de 100 grãos em resposta às doses de $\mathrm{N}$ em cobertura podem ser observados na Figura 3.

No comprimento de espiga os dados se ajustaram a uma equação quadrática, com resposta máxima na dose de $133,3 \mathrm{~kg}$ $\mathrm{ha}^{-1}$ de $\mathrm{N}$ em cobertura. O comprimento médio de espiga é um dos caracteres que podem interferir diretamente no número de grãos por fileira e, em consequência, na produtividade

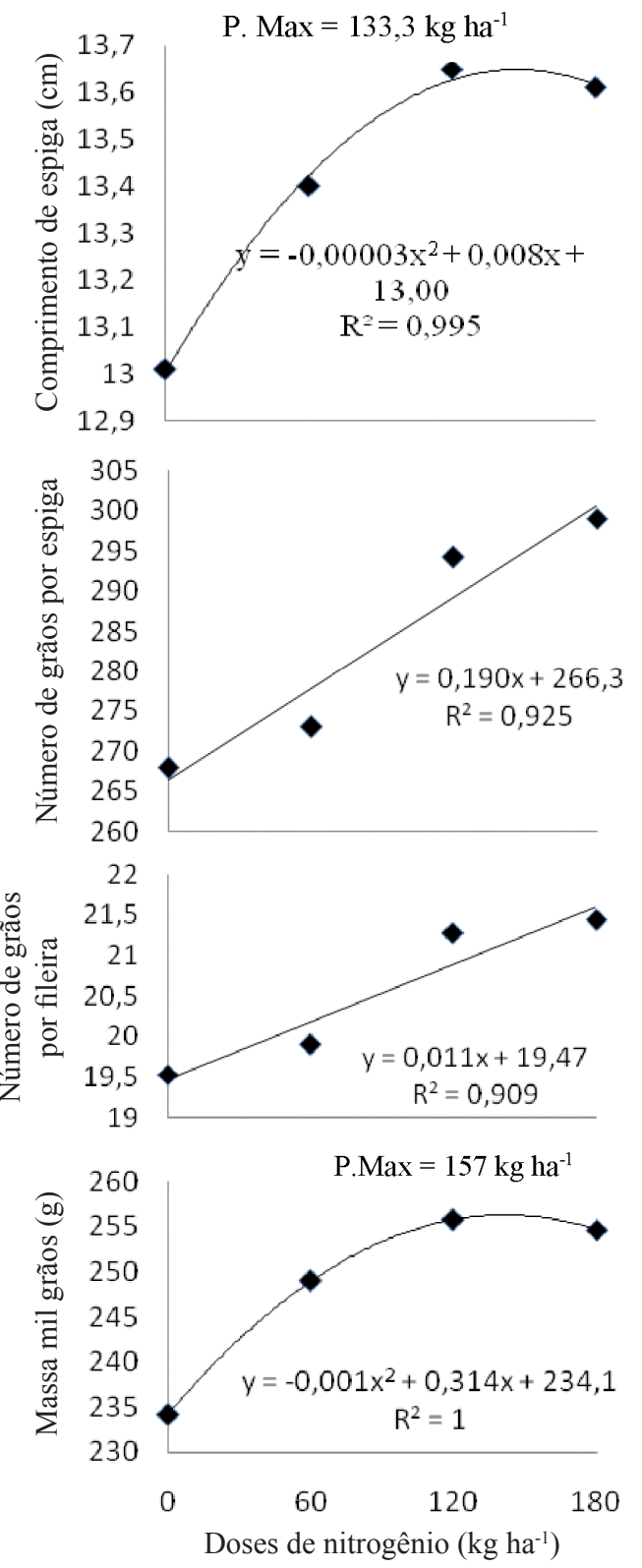

Figura 3. Comprimento de espiga, número de grãos por espiga, número de grãos por fileira e massa de 100 grãos, em função de doses de nitrogênio aplicadas na cultura do milho Safrinha 
do milho (Kappes et al., 2009) de vez que, quanto maior for o comprimento da espiga maior também será o número potencial de grãos a ser formado por fileira (Goes et al., 2012).

O incremento da resposta máxima, 133,3 $\mathrm{kg} \mathrm{ha}^{-1}$, em relação à testemunha, foi de $5 \%$ no comprimento de espigas. Para Dourado Neto et al. (2004) com a aplicação de $120 \mathrm{~kg}$ $\mathrm{ha}^{-1}$ de $\mathrm{N}$ ocorre aumento médio de $22 \%$ no comprimento das espigas em relação aos tratamentos em que a aplicação de $\mathrm{N}$ foi ausente $\left(0 \mathrm{~kg} \mathrm{ha}^{-1} \mathrm{de} \mathrm{N}\right)$ mas, ao elevar as doses de $\mathrm{N}$ de 120 para $240 \mathrm{~kg} \mathrm{ha}^{-1}$, o aumento foi pouco expressivo (3\%).

Ao avaliar a influência de doses e épocas de aplicação de $\mathrm{N}$ nas características agronômicas do milho safrinha em Jataí, GO, com quatro doses de adubação nitrogenada em cobertura: $0,20,40$ e $60 \mathrm{~kg}$ de $\mathrm{N} \mathrm{ha}^{-1}$ na forma de ureia, Ragagnin et al. (2010) concluíram que houve efeito positivo de doses de $\mathrm{N}$ em cobertura para comprimento de espigas até a dose de $40 \mathrm{~kg} \mathrm{ha}^{-1}$, para o híbrido P30S40; portanto, menor que a constatada para este estudo cuja resposta, diferenciada, pode estar associada aos genótipos utilizados e às diferentes condições climáticas entre as regiões de cultivo.

O nitrogênio aplicado na cultura proporcionou incrementos lineares positivos nas variáveis número de grãos por espiga e número de grãos por fileira. A produtividade de grãos do milho está diretamente associada a essas variáveis a qual dependerá das taxas de crescimento externadas pela cultura durante o florescimento. O N é capaz de proporcionar aumento do número de óvulos formados por fileira e favorecer a produção de fotoassimilados reduzindo, deste modo, o abortamento de grãos (Magalhães et al., 2002) resultando no acréscimo dos componentes comprimento de espiga e número de grãos por espiga, como observado na Figura 3.

$\mathrm{O}$ incremento no número de grãos por espiga obtidos neste trabalho corrobora com os dados de Soratto et al. (2010) que obtiveram aumento linear do número de grãos por espiga, do híbrido DKB 979 em razão das doses de N aplicadas em cobertura mas não verificaram efeito das fontes (ureia, Amireia , Entec ) utilizadas sobre esta característica, em Chapadão do Céu/GO.

A dose máxima utilizada, de $180 \mathrm{~kg} \mathrm{ha}^{-1}$, proporcionou $12 \%$ de incremento no número de grãos por espiga em relação à testemunha. Resultados obtidos por Amaral Filho et al. (2005) indicaram que o aumento nas doses de $\mathrm{N}(0,50,100$, $150 \mathrm{~kg} \mathrm{ha}^{-1}$ ) também promoveu aumento linear no número de grãos por espiga.

$\mathrm{Na}$ variável número de grãos por fileira o acréscimo das doses de $\mathrm{N}$ em cobertura proporcionou aumento nas médias, com 19,53,19,90, 21,27 e 21,44 grãos por fileira, respectivamente. Em seu experimento, Souza et al. (2011) observaram, ao avaliar o efeito de fontes, doses $(0,50,100$, 150 e $200 \mathrm{~kg} \mathrm{ha}^{-1}$ ) e épocas de aplicação de $\mathrm{N}$ (ureia) nas características agronômicas e na produtividade de grãos de milho safrinha irrigado com o híbrido simples AG 5020, em Selvíria, MS, que a elevação das doses de $\mathrm{N}$ aumentou o número de grãos na fileira da espiga até a dose de $142 \mathrm{~kg}$ ha $^{-1}$ de $\mathrm{N}$ menor, portanto, que a observada neste estudo mas não foi possível determinar a dose de máxima resposta.
As maiores doses (120 e $180 \mathrm{~kg} \mathrm{ha}^{-1}$ ) proporcionaram aumento de 9 e $9,8 \%$, respectivamente, no número de grãos por fileira. Resultados de Dourado Neto et al. (2004) reportam que a aplicação de nitrogênio em doses crescentes exerce grande influência no número de grãos por fileiras. Nos tratamentos em que se efetuou a aplicação de $120 \mathrm{~kg} \mathrm{ha}^{-1}$ de $\mathrm{N}$, o número de grãos por fileira foi aumentado em aproximadamente 25\% quando comparado com os tratamentos nos quais o nitrogênio não foi aplicado $\left(0 \mathrm{~kg} \mathrm{ha}^{-1} \mathrm{de} \mathrm{N}\right)$.

$\mathrm{O}$ aumento da dose de $\mathrm{N}$ aplicado proporcionou efeito positivo para a massa de mil grãos apresentando ajuste quadrático. A máxima resposta foi obtida na dose de $157 \mathrm{~kg}$ $\mathrm{ha}^{-1}$. Dados semelhantes foram encontrados por Amaral Filho et al. (2005) e Silva et al. (2005) que obtiveram aumento na massa dos grãos com a aplicação de $\mathrm{N}$ em cobertura na cultura do milho.

A massa de mil grãos é um parâmetro valoroso haja vista que se pode obter, a partir de um mesmo número de óvulos fecundados, maior produtividade apenas com o aumento das reservas acumuladas nos grãos (Silva et al., 2006). O aumento na massa de mil grãos pode ser explicado pelo fato de que as maiores doses de nitrogênio mantiveram a atividade fotossintética por um período mais prolongado, o que resultou no maior acúmulo de reservas nos grãos (Dourado Neto et al., 2004).

Sangoi \& Almeida (1994) verificaram, ao efetuar um experimento no qual aplicaram nitrogênio em doses crescentes, efeito linear da adubação nitrogenada sobre a massa de mil grãos de milho sendo que a aplicação de $150 \mathrm{~kg} \mathrm{ha}^{-1}$ de N proporcionou aumento de $7 \%$ em relação à testemunha $(0 \mathrm{~kg}$ $\mathrm{ha}^{-1}$ de N). Resposta semelhante à observada neste trabalho cuja reposta máxima de $157 \mathrm{~kg} \mathrm{ha}^{-1}$ aumentou em 8,8\% a massa de mil grãos em referência à testemunha.

$\mathrm{O}$ teor de $\mathrm{N}$ foliar e a produtividade de grãos apresentaram ajuste a uma equação linear e quadrática, respectivamente, em resposta às doses de $\mathrm{N}$ aplicadas em cobertura (Figura 4).

$\mathrm{O}$ teor de $\mathrm{N}$ foliar é um parâmetro significativo para detectar a quantidade de $\mathrm{N}$ absorvida pela planta. De acordo com Fancelli \& Dourado Neto (2008) o nível adequado do teor de nitrogênio na folha de milho para um desenvolvimento também adequado, está situado na faixa de 27,5 a $32,5 \mathrm{~g}$ $\mathrm{kg}^{-1}$. Apesar dos dados obtidos serem inferiores aos teores mencionados adequados, observa-se efeito positivo em resposta ao incremento do $\mathrm{N}$ em cobertura. $\mathrm{O}$ menor percentual incidiu sobre a testemunha com $18,3 \mathrm{~g} \mathrm{~kg}^{-1} \mathrm{e}$ maior na dose de $120 \mathrm{~kg} \mathrm{ha}^{-1}, \operatorname{com} 24,2 \mathrm{~g} \mathrm{~kg}^{-1}$. Esses dados podem estar relacionados à resposta diferenciada à adubação nitrogenada entre os genótipos, bem como às condições edafoclimáticas na condição de cultivo.

Amaral Filho et al. (2005) obtiveram aumento do teor de $\mathrm{N}$ foliar com o aumento das doses de $\mathrm{N}\left(0,50,100\right.$ e $\left.150 \mathrm{~kg} \mathrm{ha}^{-1}\right)$. Já Soratto et al. (2012) não encontraram efeito significativo para os teores de $\mathrm{N}$ foliar; entretanto, se mantiveram dentro do intervalo para a cultura (de 27,5 a $32,5 \mathrm{~g} \mathrm{~kg}^{-1}$ ). De acordo com Meira et al. (2009) plantas com maior teor de N proporcionaram maior crescimento, desenvolvimento e maior 


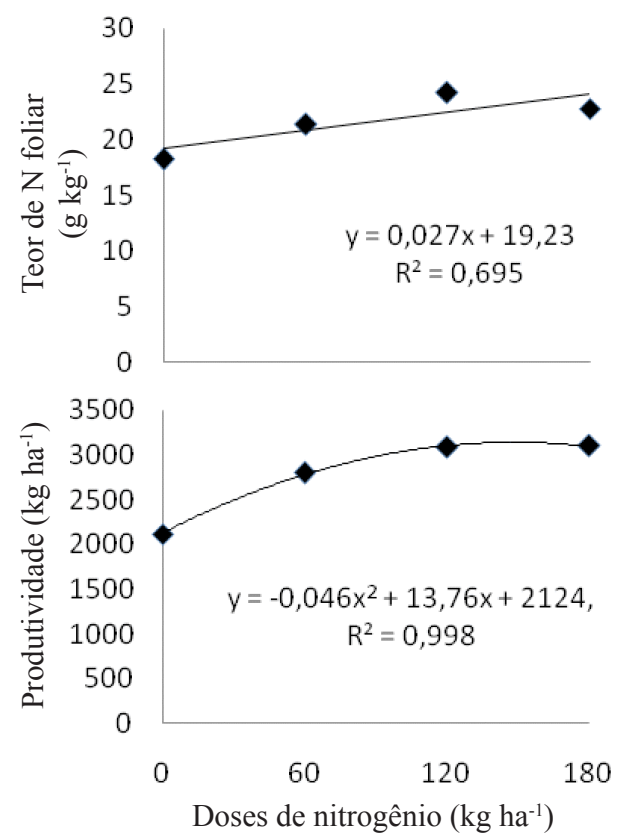

Figura 4. Teor de Nitrogênio foliar $\left(\mathrm{g} \mathrm{kg}^{-1}\right)$ e Produtividade $\left(\mathrm{kg} \mathrm{ha}^{-1}\right)$ em função de doses de nitrogênio aplicadas na cultura do milho Safrinha

índice de área foliar conferindo maior síntese de carboidratos pela fotossíntese. Assim, a planta aumenta sua eficácia em alocar carboidratos para o sistema radicular tornando-o mais abrangente e diligente em aproveitar o $\mathrm{N}$ disponível.

A resposta máxima quanto à produtividade do milho safrinha ocorreu na dose de 149,5 $\mathrm{kg} \mathrm{ha}^{-1}$, com $3107 \mathrm{~kg} \mathrm{ha}^{-1}$, acréscimo de $46 \%$ em relação ao tratamento controle. O milho é uma cultura que necessita de grandes quantidades de nitrogênio e usualmente requer o uso de adubação nitrogenada de semeadura e em cobertura para complementar a quantidade suprida pelo solo, quando se desejam produtividades elevadas (Cruz et al., 2011).

Esses dados corroboram com Dourado Neto et al. (2004) que verificaram que a aplicação de $120 \mathrm{~kg} \mathrm{ha}^{-1}$ de nitrogênio proporcionou aumento de $92 \%$ na produtividade em relação aos tratamentos em que a aplicação de nitrogênio não foi efetuada (0 $\mathrm{kg} \mathrm{ha}^{-1}$ de $\left.\mathrm{N}\right)$ ou seja, analisando a estimativa do modelo de regressão polinomial nota-se que quando a aplicação de $\mathrm{N}$ foi nula a produtividade obtida foi de 4354,7 $\mathrm{kg} \mathrm{ha}^{-1}$, ao passo que, quando foram aplicados $120 \mathrm{~kg} \mathrm{ha}^{-1} \mathrm{de} \mathrm{N}$ obtiveram-se 8379,9 $\mathrm{kg} \mathrm{ha}^{-1}$ de grãos.

Souza et al. (2011) relatam que as doses de $\mathrm{N}$ influenciaram a produtividade de grãos de milho safrinha com a máxima produtividade a $142 \mathrm{~kg} \mathrm{ha}^{-1}$ de N (aumento de $50 \%$ em relação ao tratamento sem $\mathrm{N}$ ) valor este próximo do encontrado neste estudo $\left(149,5 \mathrm{~kg} \mathrm{ha}^{-1}\right)$.

Do mesmo modo, Araújo et al. (2004) concluíram, testando diferentes doses de nitrogênio na cultura do milho, que a dose de $240 \mathrm{~kg} \mathrm{ha}^{-1} \mathrm{de} \mathrm{N}$ foi a que proporcionou maior produtividade (11203 $\mathrm{kg} \mathrm{ha}^{-1}$ ) quando comparada com a do tratamento testemunha $\left(8755 \mathrm{~kg} \mathrm{ha}^{-1}\right)$ que recebeu $0 \mathrm{~kg} \mathrm{ha}^{-1} \mathrm{de}$ $\mathrm{N}$ sendo o incremento na produtividade de grãos de $2448 \mathrm{~kg}$ $\mathrm{ha}^{-1}(28 \%)$.
A produtividade de grãos da cultura de milho dependente diretamente da atividade fotossintética da planta em que a fotossíntese, por sua vez, depende da área foliar e do tempo de permanência das folhas em plena atividade na planta (Fancelli \& Dourado Neto, 2008). Segundo Basi et al. (2011) o nitrogênio é determinante para o crescimento, desenvolvimento e rendimento das plantas já que pode influenciar nos processos fisiológicos essenciais para manutenção da vida vegetal.

$\mathrm{O}$ incremento fornecido pelo $\mathrm{N}$ nos componentes comprimento de espiga, número de grãos por espiga, número de grãos por fileira e massa de 1000 grãos mostra-se como responsável pelo acréscimo da produtividade apresentando correlação linear positiva com $r=0,994, r=0,865, r=0,879$ e $r=$ 0,997 , respectivamente (Figura 5). A produtividade depende do número de grãos polinizados e desenvolvidos e da quantidade disponível de fotoassimilados (fotossíntese). Com relação ao número de grãos, ele é variável dentro e entre cultivares e é influenciado por fatores ambientais (Magalhães et al., 2002).

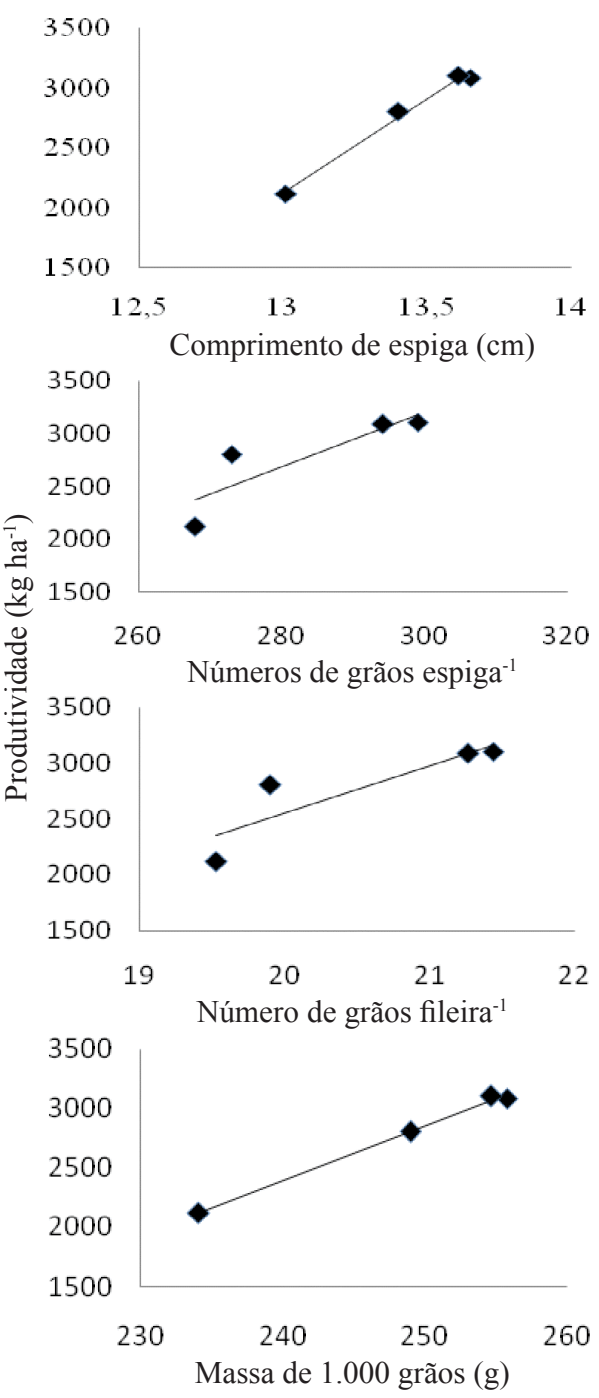

Figura 5. Correlação linear entre a produtividade $\left(\mathrm{kg} \mathrm{ha}^{-1}\right)$ e as variáveis: comprimento de espiga $(\mathrm{cm})$, número de grãos por espiga, número de grãos por fileira e massa de 1000 grãos (g) na cultura do milho Safrinha 
Durante a safrinha as condições climáticas foram coerentes com as necessidades da cultura embora a produtividade tenha sido inferior à dos híbridos modernos disponíveis devido provavelmente à diminuição da temperatura e do comprimento do dia na época de enchimento dos grãos da cultura. Cardoso et al. (2004) observaram que em alguns anos de cultivo a ocorrência de baixas temperaturas entre o florescimento e a maturação fisiológica determinou a finalização abrupta do período de enchimento de grãos no milho, decorrente das baixas taxas de crescimento que são influenciadas pelas temperaturas, o que ocorreu nas semeaduras dos meses de março e abril, mesmo período de semeadura da cultura do presente trabalho. O milho é uma planta de metabolismo C4, que apresenta alta eficiência na utilização de luz e CO2. Portanto, uma das causas da redução de produtividade do milho é a deficiência de luz em períodos críticos do desenvolvimento como, por exemplo, enchimento de grãos (Magalhães et al., 2002).

Segundo Cruz et al. (2011) o milho safrinha tem sua produtividade bastante afetada pelas limitações de água, radiação solar e temperatura em estádios avançados de desenvolvimento. A baixa produtividade do híbrido, mesmo no ponto de máxima resposta a 149,5 $\mathrm{kg} \mathrm{ha}^{-1}$, é devida também à menor disponibilidade hídrica após o florescimento da cultura visto que, em seguida a este estágio, a precipitação foi menor que a exigida para a cultura resultando em menor produção de grãos.

\section{Conclusões}

1. O produto à base de aminoácidos aplicado de forma suplementar à adubação nitrogenada não influencia nas características agronômicas nem no desempenho produtivo da cultura do milho cultivado na safrinha.

2. O nitrogênio aplicado em cobertura proporcionou efeito linear crescente para altura de plantas, altura de inserção de espiga, número de grãos por espiga e número de grãos por fileira.

3. O comprimento de espiga, a massa de mil grãos e a produtividade de grãos obtiveram, respectivamente, máxima resposta ao nitrogênio nas doses de 135,3, 157 e 149,5 kg ha-1.

\section{Literatura Citada}

Amaral Filho, J. P. R.; Fornasieri Filho, D.; Farinelli, R.; Barbosa, J. C. Espaçamento, densidade populacional e adubação nitrogenada na cultura do milho. Revista Brasileira de Ciência do Solo, v.29, p.467-473, 2005.

Araújo, L. A. N.; Ferreira, M. E.; Cruz, M. C. P. Adubação nitrogenada na cultura do milho. Pesquisa Agropecuária Brasileira, v.39, p.771-777, 2004.

Basi, S.; Neumann, M. Marafon, F.; Ueno, R. K.; Sandini, I. E. Influência da adubação nitrogenada sobre a qualidade da silagem de milho. Revista Brasileira de Tecnologia Aplicada nas Ciências Agrárias, v.4, p.219-234, 2011.

Brachtvogel, E. L.; Pereira, F. R. da S.; Cruz, S. C. S.; Abreu, M. L. de; Bicudo, S. J. População, arranjo de plantas uniforme e a competição intraespecífica em milho. Revista Trópica Ciências Agrárias e Biológicas, v.6, p.75-82, 2012.
Bremner, J. M. Nitrogen-total. In: Sparts, D. L. (ed.) Methods of gril analysis. Part 3- Chemical Methods. 1996. p.10851121.

Cantarella, H.; Marcelino, R. Fontes alternativas de nitrogênio para a cultura do milho. In: Fancelli, A. L. (ed). Milho Nutrição e adubação. Piracicaba: FEALQ, 2008. p.36-55.

Cardoso, C. O.; Faria, R. T.; Folegatti, M. V. Simulação do rendimento e riscos climáticos para o milho safrinha em Londrina-PR, utilizando o modelo ceres-maize. Engenharia Agrícola, v.24, p.291-300, 2004.

CONAB - Companhia Nacional de Abastecimento. Acompanhamento de safra brasileira: Grãos, nono levantamento, junho 2012. Companhia Nacional de Abastecimento. Brasília: CONAB, 2012.30p.

Cruz, J. C.; Silva, G. H. da; Pereira Filho, I. A.; Gontijo Neto, M. M.; Magalhães, P. C. Sistema de produção de milho Safrinha de alta produtividade: Safras 2008 e 2009.Sete Lagoas: EMBRAPA, 2011.10p. Circular técnica 160

Dourado Neto, D.; Favarin, J. L.; Manfron, P. A.; Pilau, F. A.; Soares, M. A.; Bonnecarrere, R. A. G.; Ohse, S. Efeito de boro e nitrogênio na cultura do milho. Insula, v1, p.51-67, 2004.

Fancelli, A. L.; D. Dourado Neto. Produção de milho. Guaíba: 2.ed., Agropecuária. 2008. 360p.

Goes, R. J.; Rodrigues, R. A. F.; Arf, O.; Vilela, R. G. Nitrogênio em cobertura para o milho (Zea mays L.) em sistema de plantio direto na safrinha. Revista Brasileira de Milho e Sorgo, v.11, p.169-177, 2012.

Kappes, C.; Carvalho, M. A. C. de; Yamashita, O. M.; Silva, J. A N. da. Influência do nitrogênio no desempenho produtivo do milho cultivado na segunda safra em sucessão à soja. Pesquisa Agropecuária Tropical, v.39, p.251-259, 2009.

Lana, M. C.; Woytichoski Júnior, P. P.; Braccini. A. L.; Scapim, C. A.; Ávila, M. R.; Albrecht, L. P. Arranjo espacial e adubação nitrogenada em cobertura na cultura do milho. Acta Scientiarum Agronomy, v.32, p.433-438, 2009.

Lima, M. da G. de S.; Mendes, C. R.; Nascimento, R. do; Lopes, N. F.; Carvalho, M. A. P. Avaliação bioquímica de plantas de milho pulverizadas com uréia isolada e em associação com aminoácidos. Revista Ceres, v.56, p.358363, 2009.

Magalhães, P. C.; Durães, F. O. M.; Carneiro, N. P.; Paiva, N. Fisiologia do milho. Sete Lagoas: Embrapa CNPMS, 2002. 23p. Circular Técnica, 22

Meira, F. de A.; Buzetti, S.; Andreotti, M.; Arf, O.; Sá, M. E. de; Andrade, J. A. da C. Fontes e épocas de aplicação do nitrogênio na cultura do milho irrigado. Semina: Ciências Agrárias, v.30, p.275-284, 2009.

Neumann, M.; Sandini, I. E.; Lustosa, S. B. C.; Ost, P. R.; Romano, M. A.; Falbo, M. K.; Pansera, E. R. Rendimentos e componentes de produção da planta de milho (Zea mays L.) Para silagem, em função de níveis de adubação nitrogenada em cobertura. Revista Brasileira de Milho e Sorgo, v.4, p.418-427, 2005. 
Pavinato, P. S.; Ceretta, C. A.; Girotto, E.; Moreira, I. C. L. Nitrogênio e potássio em milho irrigado: análise técnica e econômica da fertilização. Ciência Rural, v.38, p.358-364, 2008.

Picolli, E. S.; Marchioro, V. S.; Bellaver, A.; Bellaver, A. Aplicação de produtos a base de aminoácidos na cultura do trigo. Cascavel: Cultivando o saber, v.2, p.141-148, 2009.

Ragagnin, V. A.; Sena Júnior, D. G. de; Klein, V.; Lima, R. S.; Costa, M. M.; Oliveira Neto, O. V. de. Adubação nitrogenada em milho safrinha sob plantio direto em Jataí - GO. Global Science and Technology, v.3, p.70-77, 2010.

Sangoi, L.; Almeida, M. L. Doses e épocas de aplicação de nitrogênio para a cultura de milho num solo com alto teor de matéria orgânica. Pesquisa Agropecuária Brasileira, v.29, p.13-24,1994.

Silva, A. D.; Vitorino, A. C. T.; Souza, L. C. F. de; Gonçalves, M. C.; Roscoe, R. Culturas antecessoras e adubação nitrogenada na cultura do milho, em sistema de plantio direto. Revista Brasileira de Milho e Sorgo, v.5, p.75-88, 2006.
Silva, E. C. da; Buzetti, S.; Guimarães, G. L.; Lazarini, E.; Sá, M. E. de. Doses e épocas de aplicação de nitrogênio na cultura do milho em plantio direto sobre Latossolo Vermelho. Revista Brasileira de Ciência do Solo, v.29, p.353-362, 2005.

Soratto, R. P.; Costa, T. A. M. da; Fernandes, A. M.; Pereira, M.; MaruyyamA, W. I. Parcelamento de fontes alternativas de nitrogênio no milho safrinha em sucessão à soja. Científica, v.40, p.179-188, 2012.

Soratto, R. P.; Pereira, M.; Costa, T. A. M.; Lampert, V. N. Fontes alternativas e doses de nitrogênio no milho safrinha em sucessão à soja. Revista Ciência Agronômica, v.41, p.511-518, 2010.

Souza, J. A.; Buzetti, S.; Teixeira Filho, M. C. M.; Andreotti, M.; Sá, M. E. de; Arf, O. Adubação nitrogenada na cultura do milho safrinha irrigado em plantio direto. Bragantia, v.70, p.447-454, 2011. 